\title{
The Uncertainty of Students from a Widening Access Context Undertaking an Integrated Master's Degree in Social Studies
}

Authors: Dr Caroline Lohmann-Hancock \& Phillip Morgan

University of Wales Trinity Saint David

College Road

Carmarthen

Carmarthenshire

SA31 3EP

United Kingdom

Email: C.lohmann-hancock@uwtsd.ac.uk

Phone: 01267-676674

Email:p.morgan@uwtsd.ac.uk

Phone: 01267-885186

\begin{abstract}
Extending study to a fourth year in Integrated Master's Degrees (IMD) presents both risks and opportunities. This study explores students' perceptions of moving from a three-year degree to a Welsh IMD. Students initially appeared 'risk adverse' to continuing their studies to a fourthyear with many seeing this as a "gamble". The benefits identified included utilisation of loans for a fourth-year; improved career choices and increased confidence in their academic abilities. Risks identified were delayed entry into employment; suspension of income and increased student-debt. Data was collected through participatory research to "share knowledge, power and decision-making roles" (Elwood, 2006, p.119). The data challenged the negative assumption that the primary driver for exiting at Level 6 would be extended financial risk. Self-reflexive narratives confirmed the actual "gamble" was whether to "cashout' with their potentially higher existing grade at Level 6 or extend their studies and exit with a potentially lower classification (Bryant et al, 2004, p.191-192). Barriers identified include enforced altruism and unknown degree status. A constructivist approach allowed students to challenge "moral-authority"; accountability and relevance of an IMD, consider its authenticity and reflect upon potential life course trajectory and identity constructs (Benneworth, 2009 cited in Munck, 2014, p.87).
\end{abstract}

\section{Key Words:}

Non-Traditional Students; Widening Access/Participation; Employability; Risk.

\section{Introduction}


Currently within the UK Higher Education (HE) sector there has been a move towards offering students Integrated Masters' Degrees (IMDs) beyond a focus on science, engineering and law with a shift towards non-STEM subject areas (THE, 2014). This move to extend IMDs beyond the STEM disciplines allows social science and humanity students to access a fourth year of student loans whilst gaining an integrated master's degree. If these students exit at degree level and subsequently enrol on a 'standalone' master's programme they currently would incur the full costs of their studies in Wales; this is often out of reach of many potential applicants. In England, since August 2016, there has been opportunity to obtain a student loan for postgraduate study but this is only recently emerging as a potential funding option within Wales (Home Office, 2016). Postgraduate student loans in Wales are still under discussion by the Welsh Government particularly since the Diamond Review in 2016; currently student loans are now available for the 2017/18 academic year for level 7 and in 2018/19 level 8 has also been proposed (HE Review Team, 2016; SFW, 2017).

In the last decade there has been a rise in the number of students in the UK who have accessed IMDs; "for 2007-08" . . "the figure stood at just under 43,000' by 2012-13 this had risen to '79,000'” (THE, 2014). Currently within the UK HE sector 93\% of all IMDs are within the STEM disciplines with only $7 \%$ in non-STEM subjects including social science. Currently IMDs in the social sciences are represented at less than $1 \%$ of these figures (HESA, 2016). There have been concerns raised as to the efficacy of IMDs and their ability to provide "value for money' in employment terms. Initial data indicated 'that the outcomes for graduates in terms of employment were 'pretty good'” (HECSU cited in THE, 2016). As current data in the UK is limited in support of employing graduates of an integrated masters in social studies it is not possible to gauge the level of employer understanding of the reality status or perceived value to the workplace of this relatively new degree. IMDs were acknowledged as being "popular with students and employers" by the UK Government with the QAA being encouraged to promote these programmes to a wider audience including the extension to non-STEM subject areas (Great Britain: Houses of Parliament, 2012). Although now embedded in the 
British HE and European system initially the development of these degrees was limited to UK, Norway and France (Great Britain: Houses of Parliament, 2006-7: 46-48; 98).

\section{Risks of Undertaking Integrated Masters' Degrees}

Whilst the benefits of extended learning may seem obvious to institutions, students and potential employers validity regarding the worth and ability of graduates as effective professionals is dependent upon the quality of the extended programme (THE, 2014). The design of IMDs varies from a three year programme being extending into a fourth year or an additional year being added to a three year programme. Stretching an existing degree may dilute the quality of the level 7 content and in the end be just a 3 year degree over a longer period. In contrast the addition of an extra year which complements and enhances students learning through a structured progression is seen as more in line with current Masters Degrees. There are a range of perceived risks and benefits in undertaking an IMD. Historically studying an IMD within engineering, sciences and law only supported the "talented undergraduate students" (MMU, 2016). There is threshold of attainment required to allow the student to transfer to the final year of study; with this in mind for many learners enrolment at level 4 does not guarantee progression or attainment at level 7 . Within this research the MSocStud degree, and associated pathways, requires students to gain $50 \%$ at level 5 and 6 to allow for progression onto the final year of their IMDs (UWTSD, 2016: 79-80; QAA, 2015: 6). In contrast, the University of London (2016) propose enrolment on a four year programme of "social" studies from the outset, not necessarily retaining the mandate for progression by merely the "most talented". It has been suggested that "this situation reflects the independent and autonomous nature of UK higher education institutions and the diversity of traditions that exists within different disciplines" (QAA, 2010). Thus the QAA (2010) rightly outlines that "...the landscape for master's degrees in the UK is flexible and diverse...rather than to prescribe any particular model". Although the QAA (2010) guidance does requires that "master's degrees are achieved on the basis of study equivalent to at least one full-time 
calendar year (typically 180 credits) and are taken by graduates with a bachelor's degree with honours" (DBIS, 2015).

Within the political landscape of higher education the perceived merits of an IMD has had significant financial impact on HEls and their attempts to reconcile the needs of the business of education with those of students (Artess et al, 2014). Applicants and existing students considering continuing to the fourth year of study are influenced by the quality and employability of recent graduates exiting from these programmes; placing the IMDs under the microscope of decision makers thus directly impacting upon the financial stability of HEls (OECD, 2015). A DBIS (2015) report claims that the UK is "one of the few countries to have figured out a sustainable approach to higher education finance" implying that the "student finance system is good for students, good for universities and good for the taxpayer" assigning higher education a crucial space on the political agenda. It has to be noted that devolution has changed the funding landscape by country in the UK; there is currently no one funding system for the British learner. This was exemplified in the Report The Review of Higher Education Funding and student Finance Arrangements in Wales (Welsh Government, 2016) which outlined the differences and implications of a devolved HE system to fund student fees. In addition the DfEE (2000), in the document Opportunity for all: Skills for the new Economy outlined the role of the expansion in HE was "...first, to service the high-skill labour requirements of a knowledge economy; and second, to increase opportunities in both education and, subsequently, employment for groups previously under-represented in HE" (Wilton, 2011, p.86).

Within a postmodern higher education system there are both opportunities and risks associated with student learning within a world of uncertainty, "the breakdown of certainties, a feeling of crisis, and a sense of" fragmentedness, "often defined as the "postmodern condition" (Bauman, 1997, p.20). This uncertainty feeds into the apprehension of applicants and indeed students at university where targets, assessments "and standards are presented 
as 'the new faiths'" (Barnett, 2000, p.168 cited in Bartlett \& Burton, 2003, p.171). Part of this uncertainty and move towards the new faiths of assessment and employability has been visible within HEls through the growth of IMDs.

The introduction of IMDs, beyond engineering, sciences and law, affords social sciences students further choice but at the same time no assured outcomes. To support this expansion, beyond STEM subjects, further research is needed on the value of IMDs to students, employers and HEls. This will develop an understanding of a tripartite system which aims to fulfil the needs of students, employers and education providers through Labour Market Alignment (LMA) (Paulsen, 2017, p.585). Such a Neoliberal position requires a critique of the risk to reward ratio in regards to the employability of graduates, curriculum integrity and business needs. Universities and students who are engaging with IMDs remain unsure of employer perceptions of their efficacy, as they are still in their relative infancy; this is particularly the case within social science disciplines (Bowman, Hodkinson \& Colley, 2005). In regards to Quality Assurance within the international market, it has been noted that IMDs "present new requirements in terms of quality management, assessing achievements and admission criteria" (Gorzka, 2012, p.86). The major risk, as measured by HEls when students embark on an extended period of study, is primarily focused upon the financial burden to applicants. The economic support from more middle class family gives increased "personal security" in addition to student loans; whereas students from "poorer working class" backgrounds may consider the economic risk insurmountable (Bowman, Hodkinson \& Colley, 2005, p.20). The initial findings from this study contradicted the HESA (2014) results in regard to choice of degree as this cohort was less likely to be from more privileged backgrounds. Charlie Ball (HESA, 2014 cited THE, 2014), Deputy Director of Research of the Higher Education Careers Service Unit "...highlighted that the students who typically take an integrated master's are not from widening participation backgrounds". He further commented that "... if you are a student who is not terribly aware of the nuances of these courses, it might 
seem that you are paying [for] an extra year in a lot of cases, and it might not necessarily seem worth it" (THE, 2014).

Given the increased focus upon the widening access agenda alongside the introduction of IMDs this will require HEls to accommodate students who would not traditionally access a master's degree. Prior to the introduction of IMDs such students would have to independently fund their Masters level study which often meant that only those who had already graduated as well as having gained well paid employment, financial stability and professional maturity being able to engage with this higher level of study. Certainly studies suggest that Master's degrees do yield some return but for those from a widening access background this may be a risk too far (O'Leary \& Sloane, 2005). With the UK government focusing on increasing students numbers through "schemes such as Aim Higher" IMD programmes will also see a rise in nontraditional students who would not normally continue onto a master's degree (McLellan, Pettigrew \& Sperlinger, 2016, p. 57). This change to an IMD allows for students to access a fourth year of funding who would not normally go beyond a traditional degree programme (SFW, 2017). Thus to some extent there was an inequality of access to masters' degrees particularly amongst those applicants who fall within the frame of widening access as defined by HEFCW (2016a). HEFCW's (2016a) widening access agenda highlighted four inequalities which impact upon the learner's ability to access university. These inequalities include the understanding that some students, prior to applying to university, have lower educational achievement; when applying for an undergraduate place on a degree this relative educational position impacts upon the chances of successful application; in addition those who succeed in their application may exit with lower class degree or no award. Finally, the student's initial weak cultural capital may impact upon their educational understanding and ability to engage in the learning process; especially above degree level (HEFCW, 2016b; UCAS, 2014; Smithers, 2015; QAA, 2008). Currently there is minimal international or European research regarding the introduction of IMDs outside the STEM and the legal disciplines; especially within regard to widening access students (Ravi, 2015; Wiseman \& Wolhuter, 2013; Dhawan, 
2005; Arts et al, 2015; Chuguryan, 2013). This lack of research is problematic for potential IMD students, employers and HEls.

\section{Context of Study}

This study was undertaken in a Welsh HEI which has a strong focus on the Widening Access Agenda (HEFCW, 2002; 2010; 2016a). During 2015 the university took the position of developing non-STEM IMDs to allow students to benefit from accessing the fourth year of funding to continue on to master's level study and in support of extending the number of years a student is enrolled also supports HEls in financial sustainability. A number of integrated master's degrees were developed at the Welsh HEI including the Integrated Masters in Social Studies (MSocStud). This degree has three pathways Health and Social Care, Additional Needs and Communities, Families and Individual. The cohort had a higher number of nontraditional students than other degrees in the university (UWTSD, 2016). This increase in students coming from a widening access context reflected, to some degree, the programme's focus of inclusion, equality and diversity. This research explored the context of the first intake of students on the MSocStud final year of which there were 9 level 7 students and the two members of staff who teach on this programme all of whom participated in this study. This study was situated both within and outside a controlled research methods classroom environment and with a high degree of autonomy afforded to the student cohort (Vandiver \& Walsh, 2010).

\section{Methodology}

Participatory research methods were used to elicit data from the individual learning journeys of students starting the final year of their studies on the MSocStud IMD. There were two reasons for apply participatory research methods to this study 1) to ensure that students and staff were able to "share knowledge, power and decision-making roles" during the research 2) to up skill students in real life research strategies through demonstrating praxis (Clifford et al, 2010). This allowed students to "experience' the reality of community members being objects 
of the 'dominant gaze', even as they often are objects of academic research'" (Muhammad et al, 2015, p. 1055). Students were encouraged to see themselves as both actors and researchers within an authentic research team when issues of consent were explored (AboZena \& Pavalow, 2016). Thus this constructivist approach allowed students to: "challenge moral authority" through developing "trust"; explore accountability and relevance when undertaking an IMD; considering the authenticity of such a degree and finally to reflect upon the potential impact of anticipated life course trajectory and learner identity (Benneworth, 2009 cited in Munck, 2014, p.87). In addition this allowed students to develop confidence in their own ability as individuals and as research team members and the development of transferable skills for the workplace. Through a self-reflexive narrative students explored their futures in an uncertain world. This approach also resonated with the subject content of the degree where difference was celebrated and students were encouraged to enable the voice of vulnerable groups to be heard (Irving, 2010, 17; Kumashiro, 2001, 5). In addition it was essential that the two members of staff also took a self-reflexive research position to ensure that they avoided "the dangers inherent in a top-down, deterministic, blanket attribution of 'false consciousness"” (Bryant et al, 2004, p. 191-192).

The data collection methods included focus groups and qualitative interviews (Yin, 2016). These data collection tools were co-constructed between lecturers and learners through an online platform (Salmons, 2012). Initially an interview and focus group frame was developed during lectures; this was then established into a first draft by the two lecturers. Finally students edited the data capture tools online on a joint virtual learning environment in groups and pairs. These final versions of the interview and focus group frame were then discussed in a lecture and until full agreement was achieved (Phillips et al, 2013). As this is a qualitative study the results from this research are not generalizable to a wider population of students rather it focuses on the reliability of "the findings of different observers" and "between the findings of the same researcher" (Newman \& Benz, 1998, p. 46). The themes which emerged certainly raise questions which would benefit further study with a variety of integrated master's degrees in the HE sector across the UK. 


\section{Compliance with Ethical Standards}

One of the main challenges of such a research project surrounded the power relationships between students and staff who were now working 'together' as equal parties. Additionally interaction between the students as researchers also varied across the team with some only partially participating in the researcher role, ambivalent learners, and others fully engaged with both being a researcher and subject of the study (Hunter-Jones, 2012, 24). Part of the consent process explored the potential power relationships within this research which needed to be considered where the students "...should have the power to legitimate and produce the research texts that are written, as well as the power to hold researchers accountable for what is written" (Denzin and Lincoln, 2005, p. 35). In addition it was acknowledge that some students may wish to express opinions which they considered as being potentially contradictory to the position of lecturing staff. This issue was discussed both between the students as a cohort and with the staff and the decision was made that the students would interview each other and staff. This interviews were then coded to ensure anonymity which lessened the fear of offending lecturing staff to support the production of an authentic data set (BERA, 2011). The confidentiality, anonymity and the right of withdrawal and data protection was supported through applying University's Ethical Research policy and the submission of an ethics form to the University's Ethics Committee which included written consent to the inclusion in this research (UWTSD, 2017; BERA, 2011). Finally, all data collected in this study has been anonymised to ensure confidentially for all concerned; students are assigned codes $\mathrm{F} 1$ = Female 1 and $\mathrm{M} 1$ = Male 1; although the university has been identified in this study.

\section{Discussion of Results}

Whilst the limitations of this study are acknowledged, evidence gathered suggests that students' decisions to engage in extended study beyond level 6 has been largely beneficial in terms of employment, academic and personal growth criteria (Bowman, Hodkinson \& Collety, 
2005). One student commented that "...university has taught me some coping strategies which help... I feel incredibly proud of myself...now I want to do a PhD" (F 3). Students who chose to delay their planned exit from university with a BA degree and extend their studies for another academic year have all increased their grade mark, with all (accept for one) achieving a First Class Honours grade at IMD level seven this is supported, to some degree, by current employment statistics. In 2015 in the UK postgraduate employment was slightly higher than graduates and substantially higher than non-graduates with employment rates. In 2015 UK Postgraduates between $16-65$ employment rates were at $87.5 \%$, Graduates at $87.1 \%$ and Non-Graduates at $69.8 \%$; within the 21-30 year old age group employment for Graduates was $86.6 \%$, Postgraduates $87.3 \%$ and Non-Graduates at $71.6 \%$ (DfBIS, 2016, 9). This optimism was evident within the cohort in this research indicating that "I can now see that those risks were manageable and worth taking . . . I now aspire to work in a more academic or office based role rather than being a hands on carer working for a low wage" (F2).

Offering further choice to students at the end of their planned studies has presented both a significant dilemma and a positive future career path. This was particularly evident when students were asked about their reason for continuing with their studies to level 7 . Students expressed that as those who had the option of exiting with a credible degree classification at level 6 took a risk to continue to level 7 through potentially gaining a lower award outcome. Students have confirmed that late presentation of this newly developed option only served to heighten the risk to reward decision making process. Additionally there existed some selfdoubt which is traditionally common within a career-changing context external to studying at university particularly with female students; of the nine students interviewed for this study eight were female (Bedewy \& Gabriel, 2015: 2). Allied to a previously identified career pathway the option to extend further study at level 7 , whether funded or not, acted by disturbing previously identified and rationalised anticipated life-course trajectories for all students. For example F1 “...my ambitions have grown as my confidence has, I feel that this is a reflection on lecturers have shown throughout my studies, and has inspired me to achieve more". 
The opportunity was offered to all of the level 6 student cohort in the spring of their original graduation year. The time between the offer and the need to officially accept the move across to the fourth year of the IMD was of a very short duration. The need for students to make a quick decision also increased perceived weaknesses to the efficacious nature of the IMD. These doubts emerged as a form of 'post-purchase' dissonance usually associated within the buying decision making process (Koller and Salzberger, 2007). Research indicates that those individuals who have low income are more likely to be not happy with their quick decisions post purchase; as all the students in this cohort were from a range of widening access background e.g. single parents and mature returnees to education, the research expected to see dissatisfaction with their degree 'post purchase' (Hasan \& Nasreen, 2014). Students questioned both their decision to engage with IMD studies and indeed their ability to achieve an appropriate depth of academic engagement to the subject content at the required level whilst incurring further student loan debt (F2, F3 \& F1). Further concerns emerged which questioned the ability of potential employers to identify with this new qualification and academic achievement, previously unseen within social studies disciplines (F3). This indicates that there may be a need to not only educate applicants but also potential employers of the efficacy of such a degree; "I am now starting to believe that I can embark on career" (F2).

Even though students had studied under the guidance of established lecturers for the previous three years, which would continue to be so, these students considered this new option as a gamble when presented with the extended course opportunity. An element of trust in the opinion of the lecturing team was acknowledged by the group as a whole. Initial assumptions considered that the primary driver in the decision making process would be singularly financial. Evidence obtained via qualitative data capture identified that this was not the case and established that the primary driver was considered to be the gamble with their existing exit grade mark and the potential loss of status associated with a lower IMD degree classification (F1). Thus the data contradicted the assumption that financial stability and employment were essential to fund a master's qualification. In this study students stated that "...both fear of 
failure and financial risks are valid" (F1). Emerging data from this student perspective has challenged the assumption that students viewed funding and increased financial uncertainty as the major risk of undertaking the MSocStud. Rather, students indicated that the financial concerns of funding their fourth year of study was less of concern than 'other' risks. There were a number of reasons for the acceptance of all risks, both those perceived and those unknown which were "increased confidence, higher qualification to enter employment" (F2). The concerns expressed by the IMD students seems to contradict potential applicants for a MChem programme who explained via social media about their concerns in undertaking an integrated master's degree and indeed confusion regarding merits of such a programme of study. For example one potential applicant stated that "I'm going to be starting a MChem course in September, and I was just wondering, in terms of the end results (credit, employability etc.), what is the difference between an undergraduate master's and a postgraduate master's?" (The Student Room, 2016; Student Finance Wales, 2016). In a reply from the Student Room (2016) it was suggested that such degrees have both financial and status benefits for their careers. "Integrated master's degrees are considered a masters level qualification, as opposed to only a bachelors level one like a BSc. The integrated master's generally has better employability amongst technical fields, although if you want to do something that isn't directly related to your degree than just a BSc is usually fine".

Opportunities identified in the data collected in this study indicated a range of potential benefits linked to the student's future career choice; both as to the type of employment, the level of entry and potential progression within an organisation. This was associated not just with increased financial security but also job satisfaction. Many felt that if they wanted to "make a difference" it was necessary to either enter and organisation at a semi-professional or management position or progress to this level with the support of the IMD (F5). Further, students commented that the lecturing team demonstrated "a confidence that they could succeed at master's level" which was in contrast to their own initial personal view of their academic abilities. Indeed even when the students obtained "high marks" in the $70 \%$ plus 
category they still doubted that they "deserved" and indeed could "sustain" such marks (F5). In reality the students who chose to undertake the fourth year of study were highly motivated and felt that they had "committed" themselves to complete the integrated master's degree (F7). It was apparent that having fewer modules and lower student numbers contributed to a supportive learning environment. Indeed most students noted that "smaller classes", including only those students who "desired to extend their learning to level 7", benefitted the whole group's ability to progress and graduate at a higher level (M1). This progression was evidenced in the high number of $1^{\text {st }}$ class honours degrees achieved by this group (6 out of 7 students); all students including the individual who obtained a 2:1 degree also increased their overall grade mark.

Students also noted that the staff's attitude about engaging with students as fellow researchers had a positive impact upon individuals learning, giving them the confidence to "engage in academic work in more depth and to become more critical in their writing" (F4). This was expressed by one student as the ability to "have an academic voice" which was heard. The staff commented that those students who engaged in the IMD were to some degree "selfselecting" in regards to high levels of motivation and engagement (S1: S2). This, to some degree, allowed staff to teach students in an active research environment within a safe learning environment which supported students to take risks in their studies. The research project itself also up skilled students in research methods alongside a range of soft skills including team working, problem solving, decision making and critical analysis. This may have impacted upon the high level of $1^{\text {st }}$ class honours degrees in the class. The very focus of this research and the methodological stance taken could be considered, to some extent, to have influenced the grades obtain. Thus the data may have been subject to the Hawthorne Effect (Chiesa and Hobbs, 2006). Although, students commented that the supportive attitude of staff had been evident over the whole of the four year programme. It will be interesting to see the level of engagement and grades obtained by the next student cohort at level 7 . 
For non-traditional students this framework for decision making was influenced by wider concerns relating to age, ability, and confidence together with previously held and perceived negative social background inadequacies. Whilst there is some degree of commonality within the decision making process for all students it has become evident that the life-commitments of those with family responsibilities are motivated not only by the opportunity to eventually fulfil life ambitions but also to prove themselves worthy to others who may have doubted them previously. It has emerged that this need to establish a new vision of self has been in fact driven by the risk to reward potential offered within the option to extend studies beyond the traditional degree level qualification. In some instances where the student has graduated with an IMD level 7 qualification this now surpasses not only their expectations but the qualification levels of those closest to them. The commonality of both traditional and none-traditional students indicated the same concerns existed for both groups in relation to risking their current or anticipated classification and exit point after a three year degree. The majority of students surpassing the predicted classification of degree at a higher than originally expected exit point i.e. IMD Level 7. In these respects the social studies cohort report significantly differently than responses made by STEM subject students. Whereas the STEM subject students' primary driver for decision making confirmed that the financial risks were prevalent in decision making, the social studies student looked beyond this established belief reporting that the risks extended wider concluding that the personal risk to reward factors presented relied upon not only their own internal insecurities but extended outwards to include the wider aspects of uncertainty and potential lower classification albeit at a higher level of graduation.

The indictors of enforced altruism, initial relative social position and educational inequalities of earlier life opportunities have been evident, both in the responses of participant-researchers and the subsequent emergent views of "self" (Jenkins, 2004, p13). Whose assertion that identity matters as a "basic cognitive mechanism"; which in this respect enabled participants to relocate their "selves" via an extended framework of study and increased academic achievement outcomes (ibid). Despite the initial risk to reward apprehensions students 
graduating with higher than anticipated/projected degree classifications affirmed both their potential for successfully completing any degree programme and had now surpassed their initial expectations extending their confirmed abilities at a higher level i.e. An Integrated Master's degree (MSocStud) level at graduation and exit point. The behaviour patterns evident during this extended period of study appreciated the new level of status associated with that of a student researcher role, thus elevating individual student's perceived status through an increased learning opportunity and engagement at a higher academic level. Reconfigured relative and perceived statuses extended beyond the academic arena wherein the students' social and family networks acknowledged their superior comparative self. For many this relative and elevated position now placed their achievements at or beyond those of their siblings, peers and offspring. Thus confirming that for many the escape from enforced altruism had afforded them an opportunity to have their time and to have their voice heard and acknowledged; a sense of affirmation (Jenkins, 2004).

\section{Conclusion}

This paper has explored the perceived benefits and risks associated with students undertaking Integrated Masters' programmes. Students highlighted the potential benefits as: gaining a Master's degree; utilisation of full student loan entitlement; entering employment as managers and the potential of improved career choices as well as higher levels of confidence and selfesteem. Alongside these anticipated benefits learners acknowledged the risks associated with their decision. These negative factors included delay of entering employment, suspension of earned income and carrying forward increased student debt. Students considered that such factors impacted upon both their academic and career decisions and the likelihood of achieving their aspirations. This research has identified the need for widening coproduction opportunities for engagement with all students in order to increase levels of institutional understanding of their decision making processes. Specifically, if IMDs are to fulfil their potential it is imperative that reduced dissonance experienced by the student becomes a priority as enrolment is confirmed. Misunderstandings of student reasoning had led many 
academics to believe that the primary driver for decisions relating to their studies were of purely financial concern. This research has questioned this assumption as being false, eluding to the fact that other influential factors are fluid within the students developmental framework and prior levels of perceived achievement potential. Many enrolled on the traditional degree course of study expectant of only achieving a pass, confirming that a 2:1 would be a significant achievement; beyond the IMD their retrospective opinion that they were more capable than they had realised reflected not only their personal growth and ability but also reflected on the positive learning environment as being a significant factor within their decision making process.

Whilst the limitations of this research are acknowledged it remains evidenced that the changing nature of higher education provision provides both risks and opportunities for students (Findsen and Formosa, 2016). The risk being further affected by the lack of understanding amongst potential employers as to the value of a fourth year of extended learning and its potential positive impact of new employees to their organisation. Employees who might otherwise have arrived with a relative lesser skill set engage at a higher degree of agency (i.e. a BA degree qualification). Narrative evidence has presented a significant growth in the perceptions of self-associated with the higher exit qualification and whilst this is not a grand narrative it presents underpinning evidence to suggest that further research in this area would benefit both HEls and employers.

The denial of extended higher education opportunities to non-traditional students remains subject to influences both within and beyond HEls. This is despite the changing landscape of student funding and is due, in some part, to previous under-representation of 'other' types of learner/graduates on degree programmes. The success of the first MSocsStud cohort demonstrates that there remains a potential under-identified group of motivated, able and capable graduates (Gorard et al, 2007). Connor et al (1999 cited in Gorard et al 2007) confirms the perceived barriers to engagement at HE level of non-traditional students as being 
influenced by more local affections such as friends, family, transport and inflexible hours for mature and/or working students. This being the case then the successful outcomes experienced by the first MSocStud cohort far exceeds educational trajectory anticipated for disadvantaged students. Reflecting de Lemus and Stroebe's (2015) understandings this research has highlighted the underlying responses to disadvantage providing an "insight into prejudice and social disadvantage" affect the decision making process, reasoning of negative and dissonant factors preventative of extended engagement at higher education studies. Similarly the issues of coping were both an individual and a group decision; many overcoming self-doubt through the collective decision to extend learning to a fourth year and effectively gambling not only on their individual ability but additionally the improved understandings of potential employers who remain less well informed in respect of the increased validity and value in the workplace of more able graduates (Tajfel \& Turner, 1979). Who assert a comparative view that in meeting these new challenges there is evidence to affirm the view that there remains an inertia and resistance within both education (student and academics) and employers to accepting this new IM qualification since traditionally they have been restricted to STEM subject pathways (HEfCW, 2009). The previous evident acceptance of disadvantage highlighted by Leach and Livingstone (2015) has now been in part been challenged; with the initial indications of this examination to elucidate the benefits of extended and credible study experienced during a fourth year of study. The potential elevation of perceived and actual social identity has far exceeded the expectations of the participants; having confronted a negative initial social identity graduates exited with not only an improved grade classification but with an elevated perception of their social identity. With personal and academic investment by students in such integrated, degrees beyond Stem subject areas, there is a potential of delivering a more critical and robust workforce within the social sciences, both as practitioners and managers. Employers would be well placed to capitalise on a highly motivated workforce within the social care and community sector; who would be able to respond more robustly to policy for both organisations and clients in this sector. 


\section{Final Thought}

There has now been a move both in Wales and England towards the funding of Postgraduate Study from student loans. This change will certainly impact upon the efficacy of the Integrated Masters degrees currently on offer. This is especially true when one considers that currently a fulltime undergraduate degree will cost around $£ 9,000$ per annum whereas a full Master's degree is in the region of $£ 6,500$ per annum (SLC, 2017). Students will potentially exit at degree level and undertake the full masters both in terms of cost and recognisableness of a Master's degree with is understood by employers. This research will certainly support future exploration of how such non-traditional students respond to changing context of level 7 student and the potential affordability of standalone Masters versus an integrated masters degree. 


\section{References:}

Abo-Zena, M. M. \& Pavalow, M. (2016). Being In-Between: Participatory Action Research as a Tool to Partner With and Learn About Emerging Adults. Studies of Emergent Adulthood, 4(1), 19-29.

Artess, J., Ball, C., Forbes, P. \& Hughes, T. (2014). Taught Postgraduate Employability and Employer Engagement: Masters with a Purpose, Higher Education Careers Services Unit. Manchester, UK: HESCU.

Arts, J., Maloof, B., English, C. \& Woodland, B. (2015). Development of an Integrated Master's Degree and Dietetic Internship: A Collaboration between the University of Rhode Island and the Sodexo Dietetic Internships. Journal of the Academy of Nutrition and Dietetics, 115(9).

B.E.R.A. (2011). Ethical Guidelines for Education Research. London, UK: BERA.

Bartlett, S. \& Burton, D. (2003). Education Studies: Essential Issues. London, UK: Sage.

Bauman, Z. (1997). Universities Old, New and Different. In A. Smith and F. Webster (Eds.). The Postmodern University? Contested Visions of Higher Education in Society. Buckingham, UK: Society for Research into Higher Education \& Open University Press.

Bedewy, D. \& Gabriel, A. (2015). Examining perceptions of academic stress and its sources among university students: The Perception of Academic Stress Scale. Health Psychology Open, 1-9.

Bologna Process Implementation Report (2015). http://ec.europa.eu/education/policy/highereducation/bologna-process en.htm. Accessed 27 April 2016.

Bowman, H., Hodkinson, P. \& Colley, H. (2005). Employability and Career Progression for Fulltime UK Masters Students: Final Report for the Higher Education Careers Service Unit. Leeds, UK: HECSU.

Bryant, I., Johnston, R. and Usher, R. (2004). Adult Education and the Postmodern Challenge: Learning Beyond the Limits. London, UK, London: Routledge.

Chiesa, M. \& Hobbs, S. (2006). Making sense of social research: how useful is the Hawthorne Effect?. European Journal of Social Psychology. 38(1), 67-74.

Chuguryan, S. (2013). Recommendation of the Bologna Process and their Implementation to the V4 Countries. Professional Journal of Education. 4.

De Lemus, S. \& Stroebe, K. (2015). Achieving Social Change: A Matter of All for One? Journal of Social Issues. 71(3), 2015.

Denzin, N. K. \& Lincoln, Y. S. (2005) The SAGE Handbook of Qualitative Research. Thousand Oaks, California: Sage Publications. 
Department for Education and Employment. (2000). Opportunity for All: Skills for the New Economy. London, UK: Department for Education and Employment.

DfBIS. (2016). Graduate Labour Market Statistics for 2015. London, UK: OCL.

Dhawan, M. L. (2005). Issues in Indian Education. Delhi, India: ISHA Books.

Findsen, B. \& Formosa, M. (Eds.). (2016). International Perspectives on Older Adult Education. Research, Policies and Practice. London, UK: Springer Publishing.

Gorard, S., Adnett, N., May, H., Slack, K., Smith, E. \& Thomas, L. (2007). Overcoming the Barriers to Higher Education. London: UK: Trentham Books Limited.

Gorzka, G. (2012). Knowledge Transfer: The New Core Responsibility of Higher Education Institutions Practice and Perspectives in Russia and Germany. Kassel, Germany: Kassle Press.

Great Britain: Houses of Parliament. (2012). Higher Education in Science, Technology, Engineering and Mathematics (STEM) subjects - Science and Technology Committee Contents - Chapter 6: Policy Reforms. https://www.publications.parliament.uk/pa/ld201213/ldselect/ldsctech/37/3709.htm. Accessed 9 March 2017.

Hasan, U. \& Nasreen, R. (2014). The Empirical Stud of Relationship between Post Purchase Dissonance and Consumer Behaviour. Journal of Marketing Management. 2(2), 65-77. HEFCW. (2002). Commercial in Confidence. Cardiff, UK: Higher Education Funding Council for Wales.

HEFCW. (2010). Learning and Teaching and Widening Access Strategies 2011/12 to 2013/14: Initial Guidance W10/41HE. Cardiff, UK: Higher Education Funding Council for Wales. HEFCW. (2011) Learning and Teaching and Widening Access Strategies 2011/12 to 2013/14: Supplementary Guidance W11/17HE. Cardiff: Higher Education Funding Council for Wales.

HEFCW. (2011). Learning and Teaching and Widening Access Strategies 2011/12 to 2013/14: Supplementary Guidance W11/17HE. Cardiff, UK: Higher Education Funding Council for Wales.

HEFCW. (2016a). 2009. Cardiff, UK: Higher Education Funding Council for Wales.

HEFCW. (2016b). 2006. Cardiff, UK: Higher Education Funding Council for Wales.

Hill, M. \& Hatt, S. (2012). Review of Widening Access and Reaching Wider Strategies Wales. Cardiff, UK: HEA.

Hunter-Jones, P. (2012). The Continuum of Learner Disengagement: Ethnographic insights into Experiential Learning in Marketing Education. Journal of Marketing Education. 34(1), 19-29.

Irving, B. A. (2010). Developing Career Education as a Socially Just Practice. Australian Journal of Career Development. 19(3), 15-23. 
Jenkins, R (2004) Social Identity. UK: Routledge.

Koller, M. \& Salzberger, T. (2007). Cognitive Dissonance as a Relevant Construct throughout the Decision - Making and Consumption Process: An Empirical Investigation Related to a Package Tour. Journal of Customer Behaviour. 6(3), 217-22.

Kumashiro, K. K. (2001). "Posts" Perspectives on Anti-Oppressive Education in Social Studies, English, Mathematics, and Science Classrooms. Educational Researcher. 30(3), 3-12.

Manchester Metropolitan University. (2016). Integrated Masters. http://www.scieng.mmu.ac.uk/courses/undergraduate-courses/integrated-masters/ Accessed 27 April 2106.

McLellan, J., Pettigrew, R. \& Sperlinger, T. (2016). Remaking the Elite University: An Experiment in Widening Participation in the UK. Power and Education. 8(1), 54-72.

Muhammad, M., Wallerstein, N,. Sussman, A. L., Avila, M., Belone, L. \& Duran, B. (2015). Reflections on Researcher Identity and Power: The Impact of Positionality on Community Based Participatory Research (CBPR) Processes and Outcomes. Critical Sociology. 41(7-8), 1045-1063.

Newman, I. \& Benz, C. R. (1998). Qualitative-Quantitative Research Methods: Exploring the Interactive Continuum. Carbondale \& Edwardsville, IL: Southern Illinois University Press.

O'Leary, N. C. \& Sloane, P. J. (2005). The Return to a University Education in Great Britain. National Institute Economic Review. 193, 75-89.

Parliament. (2007). Education and Skills Committee demand European Commission Role to be constrained in Higher Education Plans. http://www.parliament.uk/business/committees/committees-archive/education-andskills-committee/espn300407/. Accessed 13 April 2017.

Phillips, L., Kristiansen, M., Vehviläinen, M. \& Gunnarsson, E. (2013). Knowledge and Power in Collaborative Research: A Reflexive Approach. New York, NY: Routledge.

Q.A.A. (2010). Master's Degree Characteristics, Gloucester, UK: The Quality Assurance Agency for Higher Education.

Ravi, V. (2015). Comparative Educational. Raleigh, NC, USA: Lulu Publications.

S.F.W. (2017). New Students. http://www.studentfinancewales.co.uk/newstudents.aspx\#.WMLMWdLyics. Accessed 10 March 2017.

S.F.W. (2017). Postgraduate Loan for Master's degrees. Student Finance Wales. http://www.studentfinancewales.co.uk/postgraduate-loan.aspx\#.WO9KRUXythF. Accessed 13 April 2017.

Salmons, J. (2012). Cases in Online Interview Research. Thousand Oaks, CA: Sage. 
T.H.E. (2014). Surge in Popularity of Two-in-One Degree Courses: Student loans access for a master's qualification througt to be principlae cause. https://www.timeshighereducation.com/news/surge-in-popularity-of-two-in-one-degreecourses/2014853.article. Accessed 13 April 2017.

The Student Room. (2016). The Student Room. http://www.thestudentroom.co.uk/showthread.php?t=1728967. Accessed 27 April 2016. The Times Higher Education. (2014). Surge in Popularity of Two-in-One Degree Courses. https://www.timeshighereducation.com/news/surge-in-popularity-of-two-in-one-degreecourses/2014853.article. Accessed 17 November 2016.

University of London. (2016). MSoc Sociology Integrated Masters. https://www.uel.ac.uk/Undergraduate/Courses/MSoc-Sociology-Integrated-Masters. Accessed 27 April 2016.

University of Wales Trinity Saint David. (2015) Research Integrity and Ethics Code of Practice. http://www.uwtsd.ac.uk/media/uwtsd-website/contentassets/documents/research/Research-Integrity-and-Ethics---Code-of-Practice-(201518).pdf. Accessed 15 June 2015.

Vandiver, D. M. \& Walsh, J. A. (2010). Assessing Autonomous Learning in Research Methods Courses: implementing the Student-Driven Research Project. Active Learning in Higher Education. 11(1), 31-42.

Welsh Government. (2016). HE Review Team 'Review of Higher Education Funding and Student Finance Arrangements in Wales: Final report - Executive Summary. Cardiff, UK: Higher Education Division - Skills, Education and Lifelong Learning Directorate.

Wiseman, A. W. \& Wolhuter. C. C. (2013). The Development of Higher Education in Africa: Prospects and Challenges. International Journal on Education and Society. 21.

Yin, R. K. (2016). Qualitative Research from Start to Finish. New York, NY: The Guildford Press.

Elwood, S. (2006). Negotiating Knowledge Production. The Everyday Inclusions, Exclusions, and Contradicitions of Participatory GIS Research. 58(2), 197-208.

Munck, R., Mcllrath, L., Hall, B. \& Tandon, R. (2014). Higher Education and Community-Based Research: Creating a Global Vision. Basingstoke, Hamps, UK: Palgrave MacMillan. 